\title{
Technology-mediated personalised learning for younger learners: concepts, methods and practice
}

Stefanie Vanbecelaere

KU Leuven, itec,

research group of imec

Kortrijk, Belgium

stefanie.vanbecelaere@kuleuven.be

\section{Fien Depaepe}

KU Leuven, itec,

research group of imec

Kortrijk, Belgium

fien.depaepe@kuleuven.be

\section{Frederik Cornillie}

KU Leuven, itec,

research group of imec

Kortrijk, Belgium

frederik.cornillie@kuleuven.be
Mina Vasalou

UCL Knowledge Lab

London, United Kingdom

a.vasalou@ucl.ac.uk

Roger Gilabert Guerrero

UCL Knowledge Lab

London, United Kingdom

rogergilabert@ub.edu

Manolis Mavrikis

UCL Knowledge Lab

London, United Kingdom

m.mavrikis@ucl.ac.uk

\section{Laura Benton}

UCL Knowledge Lab

London, United Kingdom

I.benton@ucl.ac.uk

Permission to make digital or hard copies of part or all of this work for personal or classroom use is granted without fee provided that copies are not made or distributed for profit or commercial advantage and that copies bear this notice and the full citation on the first page copyit for third for third-party components of this wh

CHI 2020 Extended Abstracts, April 25-30, 2020, Honolulu, HI, USA.

C) 2020 Copyright is held by the owner/author(s).

(C) 2020 Copyright is held by the owner/a

DOI: https://doi.org/10.1145/3334480.XXXXXXX

*update the above block \& DOI per your rightsreview confirmation (provided after acceptance)

\section{Abstract}

Children differ in various aspects such as prior knowledge, learning pace, socio-economic status, interests etc. It has been argued that when we take these differences into account when we develop learning environments, children will benefit from it in terms of learning outcomes, learning experience, and attitudes towards particular subjects. The emergence of digital technologies has accelerated the movement to create personalised learning environments. Although technology-mediated personalised learning is

promising, several challenges remain such as how personalised learning should be conceptualized, which methods should be used to establish the effects and how this movement impacts education and especially children and teachers. This workshop aims to bring together researchers and practitioners who have done work in this field to facilitate in-depth discussions, resource exchange and networking on technologymediated personalised learning.

\section{Author Keywords}

personalized learning; children; digital technologies

\section{CSS Concepts}

- General and reference Cross-computing tools and techniques Measurement; Evaluation; Design 
- Applied computing Education Computer-assisted instruction; Interactive learning environments

- Human-centered computing Human computer interaction $(\mathrm{HCI}) \sim$ Empirical studies in $\mathrm{HCI}$

\section{Introduction}

Nowadays, teachers are faced with increasingly diverse classes in terms of children's prior knowledge,

motivation, language, socio-economic status etc. This is not only due to globalization but also to the tendency of inclusive education where all students are welcomed, are involved in all aspects of school life and are expected to attend and participate during regular classes. This diversity leads to increasing difficulties for teachers to develop learning activities which address each child's individual needs because of a lack of resources, time, flexibility, etc. [4]. In this regard, the emergence of digital technologies has raised new opportunities to establish personalised learning. Affordances of digital technologies are that they can provide among others individual and immediate feedback, non-linear access, choice and interactivity [10]. As before whole-class instruction (one-size-fitsall) was widespread, there is now a shift to personalised learning addressing individuals' needs by providing tailored support [6]. Intelligent tutoring systems and exploratory learning environments are two examples through which technology-mediated personalised learning can be established [8]. Although technology-mediated personalised learning has been the goal of many innovative projects, so far, research mainly focused on the implementation of it, often neglecting the pedagogical perspective. The aim of this workshop is four-fold:
- The concept of technology-mediated personalised learning will be explored to develop a shared understanding.

- The process of designing personalised technology will be discussed. More particularly how the interplay between technical competence, subject domain and cognitive modelling expertise can add value to this process.

- As evidence of the effects on children's learning is scarce, the design and empirical methods that are currently used will be analyzed.

- We aim to have more insights in how technologymediated personalised learning impacts teachers and schools.

In what follows, we discuss the issues which will be addressed during the workshop.

\section{Theme 1: Towards a definition of personalised learning}

To design and develop technology-mediated personalised learning, it is important that we understand what this concept means. The literature on personalised learning has highlighted several definitions. For example, it has been defined as "a technology-based instructional model designed to tailor instruction to student needs, strengths, and interests to promote mastery of skills and content" [4, p. 455]. Although there is not yet one definition of personalised learning, several researchers identified important characteristics of technology-mediated personalised learning. While some researchers emphasize that the learner becomes central during learning in terms of choice, responsibility, personal relevance, student voice $[3,6]$, other researchers stress the control that is exercised by the program/system and which is related to few learner choice/responsibility [13]. [8]

characterized personalised learning across a set of 
continuums. Furthermore, different concepts have been related to personalised learning such as differentiated instruction, individualized learning, adaptive learning, without clearly demarcating their boundaries. [14] elaborated on the differences/similarities between adaptive learning and personalised learning - they stated that it is difficult to distinguish between them in the scope of technology-enhanced learning (here technology-mediated learning). The goal of this workshop is to contrast the existing definitions and characteristics of technology-mediated personalised learning in order to develop a shared understanding of this concept.

\section{Theme 2: Designing personalised technology}

The design of personalised technology is a process that requires, apart from technical competence, extensive subject domain and cognitive modelling expertise. However, despite the advances in the field of artificial intelligence and related research, there is a disconnect between the state-of-the-art and what the current systems used at scale are demonstrating (c.f. [2], 2019 who makes a similar argument for adaptive educational technology). When thinking of personalised learning for younger learners and technology in particular, one challenge that emerges is that the expertise required to inform, for example, sequencing or other adaptive strategies, is not readily available in the form or precise and explicitly formulated knowledge. As such, methods are needed to provide access to experts' 'tacit' knowledge and experiences [12]. Commonly used methodologies are usually iterative and revolve around a design-based research paradigm. These include approaches referred to as learner-centered design [7], Persistent Collaboration Methodology (PCM) [5] and iterative communication capacity tapering [9]. Methods for designing personalised technology tend to yield instructional and domain knowledge, that differs from the methods traditionally used in Interaction Design e.g. where the complexity around people's lived experiences, or creative ideas is the focal goal. The workshop will provide an opportunity for designers and other researchers to reflect on such approaches and particularly on practical lessons learnt from using such approaches and tools.

\section{Theme 3: Methodologies for evaluation}

Another important issue are the methodologies that are applied to evaluate the effectiveness of personalised learning. Although there is an increased interest from research, governments and edtech companies in personalised learning, only a limited number of studies have focused on the children's learning effects $[8,14]$. This is problematic because only ongoing evidenceinformed research will show whether the implementation of personalised learning is justified [6]. [1] suggested that the effectiveness can be determined based on cognitive, non-cognitive and efficiency learning outcomes. In addition, some methodological concerns were identified with previous intervention studies ranging from the tests that are used (e.g. whether they are standardized) to the study design (e.g. choosing groups, treatments). During the workshop, our goal will be to develop a better understanding of methodology and the opportunities for digital data to evidence learning. Different research designs will be compared with the aim to enlarge researchers' desire to strengthen their knowledge about methodologies for evaluation. By doing so, special attention will be given to the use of logging data and the parameters that might be informative. In addition, difficulties with taking measures in young children will 
be identified, and how we might overcome these difficulties by the use of unobtrusive data.

\section{Theme 4: Impacts of personalised learning}

Finally, in the workshop we will look beyond

effectiveness to consider how personalised learning can change how we understand practice and research. The implementation of technology-mediated personalised learning changes the dynamic of the classroom, as such it impacts on learners and teachers [3]. One of the hypes is that future personalised learning will be more self-initiated and will take place through personal learning paths in flexible learning environments; thus, in this context, teachers will be expected to make decisions based on real-time data [11]. This introduces new questions such as, how may teachers re-interpret adaptivity? How will they make decisions on the learning process based on the data that is provided by the system? What is the social acceptance of these technologies and how can we communicate their benefits to different stakeholders? In relating the realtime and long term of personalised learning to research, there are additional implications. Personalised learning technologies are often designed based on domain-specific studies, traditionally studied through other empirical methods. Knowledge of the domain is limited to the methods we have available. How can data from personalised learning contribute to new forms of knowledge, such as for instance in how to sequence learning?

\section{Organizers}

The organizing team brings together expertise in pedagogy, personalised learning, AI and interaction design. Additionally, the team cuts across different disciplines involved in research around the topic.
Stefanie Vanbecelaere is part of the Centre of Instructional Psychology and Technology and the ITECimec research group at KU Leuven campus Kulak Kortrijk. She is currently pursuing a PhD that focuses on investigating the effectiveness of adaptive educational games for the development of math and reading in young children. Currently, she is involved in the $\mathrm{i}$-Learn project (https://i-

learn.vlaanderen/\# contact) which aims to develop a platform with tools that support personalised learning which will be used by primary and secondary schools in Flanders.

Mina Vasalou is associate professor in interaction design at the UCL Institute of Education, UCL Knowledge Lab. Mina has participated in a number of projects around the theme of personalised learning, including the EU Horizon 2020 project iRead. Mina's research focuses on the area of design for educational technologies, both reflecting on how design can best support learning and methods that involve teachers, students and parents in the design process.

Frederik Cornillie works in the field of computerassisted language learning (CALL). His research aims are to uncover the mechanisms that support effective and engaging second language (L2) learning in instructed contexts (classrooms and beyond), with particular attention to the impact of explicit instruction, practice, and feedback on L2 development. Currently, he is research manager of ITEC (research group of imec) at the campus kulak of the University of Leuven. He coordinates projects within the field of digital innovation in education, including the Smart Education @ Schools programme which involves teachers in primary and secondary education in Flanders in co- 
designing and -developing educational technology for their learners.

Fien Depaepe is associate professor at the Faculty of Psychology and Educational Sciences and affiliated to the Research unit Center for Instructional Psychology and Technology (CIP\&T). She is principal investigator of the imec KU leuven interdisciplinary research group ITEC. She supervises researchers on topics of instructional design and evaluation of technologyenhanced learning environments. In these different projects multimodal data (self-reports, assignments, logdata, physiological, and audiovisual data) is used to model students' learning.

Roger Gilabert Guerrero is a professor and researcher within the Language Acquisition Research Group (GRAL) at the University of Barcelona (UB). He's currently involved in research into multimodal learning (second language learning through subtitles and captions in TV series) and he leads the UB team within an EU-funded project on personalised, game-based technologies and reading skills (iRead). Roger Gilabert has also published extensively in the areas of task design, task complexity, task sequencing and syllabus design.

Manolis Mavrikis is associate professor in Learning Technologies at the UCL Institute of Education, UCL Knowledge Lab. His main area of research is personalised learning and the use of data in education. Combining quantitative approaches from educational data mining and theories from education, his work contributes new design tools that augment the creativity and decision-making for teachers and students. Dr Mavrikis has been principal investigator on a portfolio of large interdisciplinary EU projects on technology-enhanced personalised learning, most notably the award-winning iTalk2learn

https://www.italk2learn.com/.

Laura Benton is a research associate working full-time on the iRead project, an EU-funded project led by UCL aiming to develop personalised learning technologies to support reading skills at primary school. Her research interests span the areas of user-centred design, childcomputer interaction, ed-tech, literacy and children's programming. Her research focuses on education technology design for children and she has worked on several projects using design approaches such as participatory design and design-based research, including iLearnRW and ScratchMaths.

\section{Website}

A website is developed to promote the workshop in the research and edtech community and to inform the participants about the details of the workshop:

https://stefanievanbecelae.wixsite.com/personalisedlea rning. The workshop consists of (1) general information about how it is a part of the IDC conference, (2) a detailed program of the day, (3) who is targeted and what is required from participants, (4) information about the organizing team and (5) contact details.

\section{Pre-Workshop Plans}

Through their work, the organizers have an extensive network of collaborators working in this area. Recruitment will happen through word of mouth. Additionally, we will approach mailing lists and social media e.g. IDC/Child-Computer Interaction. Through these means, and our website, we will take an inclusive approach to the attendees welcoming researchers 
across disciplines and industry practitioners.

Participants will be invited to submit a portfolio of three short contributions that will be used to stimulate discussion during the workshop: definitions of personalised learning, a design or empirical method they have used and their reflections, and reflections from field research.

\section{Workshop Structure}

This will be a whole day workshop designed to engage participants through different types of activities.

- 10-11am (Theme 1 definitions): Panel of invited speakers and plenary discussion on definitions of personalised learning

- 11-11:30am Coffee break and demonstrations of attendee's personalised learning tech

- 11:30-12:30

(Theme 2 design): Break out groups to discuss current approaches to designing personalised learning.

- $\quad 12.30 \mathrm{pm}-1.30$ Lunch break

- $\quad 1.30-2.30$

(Theme 3 methodology): Break out groups with demonstrations of methodological designs, reflection on the different designs and identification of drawbacks/benefits

- 2:30-3:00 Coffee break

- 3:00-4:00

(Theme 4 impacts): Break out groups to identify the impacts of personalised learning for different groups of people and the questions raised. Participants will introduce reflections from their own research

\section{Post-Workshop Plans}

The outcome of the workshop will be a conceptual map of current work, challenges identified and a future agenda for research in personalised learning through technology. The organizers plan to publish the outcomes as a journal paper. In addition to this, we will plan a special issue either in the British Journal of Education Technology (co-editor: organizer Manolis Mavrikis) or the International Journal of Child-

Computer Interaction (associate editor: organizer Mina Vasalou).

\section{Call for Participation}

This is a full day workshop that seeks to map out current research and future goals for those involved in designing and understanding the impact of technologies for personalised learning. Academics and practitioners who have done work in this area are invited to participate. The workshop will focus on the following themes: definitions of personalised learning, methodologies for design and evaluating, impacts of personalised learning on pedagogy and research. The workshop will engage participants in hands on activities and round table discussions. To facilitate this,

submissions will consist of a short portfolio up to 1,000 words including (1) a definition of personalised learning you use to guide your research (2) a design method or empirical methodology you have experience with and reflections on how it worked (3) evidence on the impacts you have observed on personalised learning for research or practice. In addition to this, on the day there will be space for those who have technology demonstrations to showcase their work. Detailed information on the workshop, its goal and the submission requirements appear on the workshop website: 
https://stefanievanbecelae.wixsite.com/personalisedlea rning

\section{References}

[1] All, A., Castellar, E. P. N., \& Van Looy, J. (2015). Towards a conceptual framework for assessing the effectiveness of digital game-based learning. Computers \& Education, 88, 29-37.

[2] Baker, R.S.: Stupid Tutoring Systems, Intelligent Humans. International Journal of Artificial Intelligence in Education 26(2), 600-614 (Jun 2016).

[3] Basham, J. D., Hall, T. E., Carter Jr, R. A., \& Stahl, W. M. (2016). An operationalized understanding of personalised learning. Journal of Special Education Technology, 31(3), 126-136.

[4] Bingham, A. J., Pane, J. F., Steiner, E. D., \& Hamilton, L. S. (2018). Ahead of the curve: Implementation challenges in personalised learning school models. Educational Policy, 32(3), 454-489.

[5] Conlon, T., \& Pain, H. (1996). Persistent collaboration: a methodology for applied AIED. Education, 7, 219-252.

[6] FitzGerald, E., Kucirkova, N., Jones, A., Cross, S., Ferguson, R., Herodotou, C., ... \& Scanlon, E. (2018). Dimensions of personalisation in technology-enhanced learning: A framework and implications for design. British Journal of Educational Technology, 49(1), 165-181.

[7] Good, J. and Robertson, J. (2006). CASS: A framework for learner centred design with children. Int. Journal of Artificial Intelligence in Education, 16.

[8] Holmes, W., Anastopoulou, S., Schaumburg, H., \& Mavrikis, M. (2018). Technology-enhanced personalised learning: Untangling the evidence.
[9] Mavrikis, M., \& Gutierrez-Santos, S. (2010). Not all wizards are from Oz: Iterative design of intelligent learning environments by communication capacity tapering. Computers \& Education, 54(3), 641-651.

https://doi.org/10.1016/j.compedu.2009.08.033

[10] National Academies of Sciences, Engineering, and Medicine. How people learn II: Learners, contexts, and cultures. National Academies Press, 2018.

[11] Pane, J. F., Steiner, E. D., Baird, M. D., \& Hamilton, L. S. (2015). Continued Progress: Promising Evidence on Personalised Learning. Rand Corporation.

[12] Porayska-Pomsta, K., Mavrikis, M., D’Mello, S., Conati, C., Baker, R.S.: Knowledge elicitation methods for affect modelling in education. International Journal of Artificial Intelligence in Education 22(3), 107-140 (2013)

[13] Vandewaetere, M., \& Clarebout, G. (2014). Advanced technologies for personalised learning, instruction, and performance. In Handbook of research on educational communications and technology (pp. 425-437). Springer, New York, NY.

[14] Xie, H., Chu, H. C., Hwang, G. J., \& Wang, C. C. (2019). Trends and development in technologyenhanced adaptive/personalised learning: A systematic review of journal publications from 2007 to 2017. Computers \& Education, 140, 103599. 